\title{
The Effectiveness of Automated Machine Over Manual Machine in Operational Line
}

\author{
https://doi.org/10.3991/ijoe.v17i12.24729 \\ Helmi Adly Mohd Noor ${ }^{1(\bowtie)}$, Muhamad Nor Sadiqin Bin Ramli ${ }^{1}$, Rahimah Kassim ${ }^{1}$, \\ Fauziah Abdul Rahman ${ }^{2}$, Zirawani Baharum ${ }^{1}$, Farah Idayu Mohd Salleh ${ }^{1}$ \\ ${ }^{1}$ Universiti Kuala Lumpur - Malaysia Institute of Industrial Technology, Johor, Malaysia \\ ${ }^{2}$ Universiti Teknikal Malaysia Melaka, Melaka, Malaysia \\ helmiadly@unikl.edu.my
}

\begin{abstract}
This project research will concentrate more on the effectiveness of machine over manual machine in operation line at LGL Technology Sdn Bhd. Hence, based on the research problem regarding the effectiveness of LGL operation, it will be necessary to investigate on the operations that are mostly manual machine dependent. Therefore, the researchers decided to exert two research techniques in order to get the information. The first source is the primary sources that include observation and interview. The secondary sources are based on journals, websites, books and articles. Simulation technique was used to mimic the real-world system on the computer and creating a simulation on the current and the proposed design to compare which is more effective to be used. Thus, in the future this project would be able to help the LGL to improve the effectiveness in their operation and it can also improve their service to their customer.
\end{abstract}

Keywords—operation, manual machine, simulation, service improvement

\section{Introduction}

LGL Technology Sdn Bhd is a branch for Southtec Precision Engineering Sdn Bhd. LGL technology produce goods based on the customer drawing. This is because they are producing precision item or fabrication item. This type of item requires a precise procedure and time to produce it. That is why LGL Technology Sdn Bhd needs to consider the changes from using manual machine to automatic machine as it will be benefit to them and also to their customer.

In manufacturing industries, quality and time is important as to ensure they can keep on fulfill the customer order. For getting the service quality, its start from the operation line in the company [4]. If the company have an effective operation line, the company will have a good service quality to be served to the customer. As for the precision item, there is a need for the item to be in a good quality to ensure customer satisfaction.

This research is conducted to identify the effectiveness of automated machine over manual machine in the operation line. This research will be conducted at LGL Technology Sdn Bhd. This manufacturer company serves around Johor Bahru. 
In order to obtain a high level of customer satisfaction, it should start from the company operation line that needs to be effective on managing the customer goods so it can manage the number of orders received by the company. Based on the observation, the company needs to change from using manual to automatic machine in the operation line to ensure the effectiveness of managing customer goods.

\subsection{Problem statement}

LGL technology is one of the well-known fabrication item providers in Johor Bahru; to maintain their customer loyalty they need to maintain the services on providing great finished product to customer so that the customer will always trust in their effectiveness of service [9]. Based on the current situation, LGL technologies have a low number of automated machines to improve their effectiveness.

Currently, LGL technology are facing issues with their operational line and to solve the problem, the company has taken the necessary action by increasing the number of machines, but they only increase the number of manual machines. By increasing the number of manual machines, it still caused a problem to the operational line to have a worker that are truly expert in handling certain type of manual machine. Fabrication items need a good precision machine to ensure the result as desired by the customer.

The effectiveness of both manual machine and automated machine can be evaluated by using simulation method. By using the simulation software, the company able to know which one is better and could be implemented into real world so that the problem can be solved [6]. IoT is one of the solutions to minimize the energy consumption within the city as well as reduce the crews on site in maintenance processes [14].

By using the simulation to increase the effectiveness of company, LGL can refurbish their effectiveness in terms of time and output.

\subsection{Research objective}

The aim of this research is to identify the effectiveness of automated machine over manual machine in operation line. According to the background of the study there are three research objectives. The research objectives that would like to be achieved are:

1. To study the existing effectiveness of manual machine in LGL technology.

2. To develop a simulation on the effectiveness of automated machine and manual machine.

3. To evaluate the different about the effectiveness of automated and manual machine in terms of time and output.

\section{Literature review}

\subsection{Production}

Production can be defined as the process and methods used to transform tangible inputs (raw materials, semi-finished good) and intangible inputs (ideas, information, 
knowledge) into goods or services [2]. These are important elements in the manufacture process that enable the raw output to be made as accordingly based on the production procedure and safety precaution flows.

\subsection{Effectiveness of machine and manpower}

In operation nowadays, the manpower usually used to manage the handling in the operation but after many tasks the human essentially imitates the machine such as handling and scanning of goods. The manpower or human will be tired, and they will start on making some mistake. To overcome this problem, human needs to accept the machine as to perform this type of activity. The machine is better with a repetitive and mechanistic task. For example, an activity in the operation line such as transfer the goods from the actual location to the final destination in the other department by using human strength can affect their health, for example it can give a long-term back pain to the human. But Gorbis, (2011) [3] on man versus machine: 9 human jobs taken over by machine, factory workers are in the list due to technological intervention, to ensure the factory can operate in heavy labor compared on using the manpower. For example, one of the companies in China has replaced $90 \%$ of their workers with robots due to reduction of the defect and to increase the production because machine have many advantages compared to manpower such as it can carry out the task on their own and only need few humans to monitor the machine [5]. A further advantage of the machine is the cost policy of the manufacturer [15].

Increase of effectiveness - in the operation line if there is a change from using manpower into a machinery operation line, it can increase the effectiveness of the operation due to the speed of the machine that is more superior to the manpower that are comparatively slow on handling goods. In terms of power output, the machine is more superior on managing the work compared to human because if the human keep doing the same thing or in a long term it can make the human feel tired. In terms of consistency, machine is more consistent compared to human in making something repetitive action and human will easily fatigue [1]. According to Mohd Noor, H. A, (2020) [7], increasing and upgrading the existing machine can improve the production process of palm oil mill. The combination of training and tools to assist the worker can improve the harvesting productivity. For manpower, it is also effective in terms of it is easier to program [1], for certain work that are almost impossible for machine, according to makeuseof.com such as quality assurance due to machine can be breakdown, metal rust, $\operatorname{cog}$ can wear and out that will affect the quality so it will need a human on spot affect. the adoption of cutting-edge technologies for conducting business activities not only offers competitive advantages. It also provides a means for survival during community lockdown because of the pandemic [16].

\subsection{Simulation model}

Many technologies now urge the manager to use this simulation model to test new ideas and option before implementing the actual ideas. Instead of using the expensive mathematical model, the manager can use the simulation models or the readily 
simulation software that are possible to make a model and analyze the operation of a real system. In terms of operation, before proceed using the machine, the manager can use the simulation as guidance to make a model that allow the manager to both quantify and also to observe the system behavior. The simulation can be used for the system such as production line, distribution network and also a communication system. By using the simulation, the manager can evaluate the current operation and also compare it with the new idea that is simulated by seeing the input of the simulation. The simulation is made affordable for the company and also easy for the manager to simulate any of situation operation, process, feasibility study, business process, human resource and others [8]. Simulation models are to represent some part of real world to ensure the experiment that using the simulation are accurate predictor of the reality [9].

\subsection{Benchmarking}

According to businessdictionary.com benchmark is a set of standards that are used as a point of reference for evaluating performance or level of quality. Before making the simulation for certain company, there are companies that already using witness simulation as a system that help in their business such as:

Nissan automotive company. Nissan got a new battery plan in UK. The need of the modelling is to answer the key question that is whether to follow a proven existing design from Japan or use a new one. A new design should be more space savings, use less resource and will require less capital investment compared to existing design. Their contractor Daifuku and Nissan modelled the facility in witness by making many options and then it comes to savings in equipment and operating cost of 2.5 million euros [10],[11],[12].

In their simulation, Nissan make a bush press robot cell model that is four types of part each with different build sequence and robot process duration. Witness optimizer is used to optimize sequence of part to minimize the cycle time. It gives a $3 \%$ better answer compared to previous best calculated solution. Below is the figure of Nissan witness simulation.

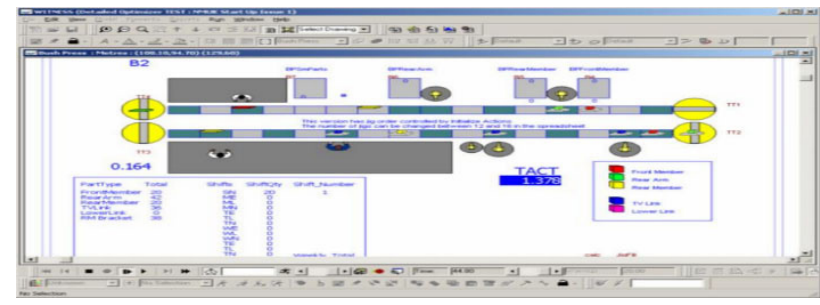

Fig. 1. Nissan automotive model

Supply chain-Coca Cola. Coca Colas use witness simulation as a solution for their supply chain. At early 2010 they only can produce 30,000 bottles per hour at the factory in UK. They are planning to increase the production by 20 to 30 percent. By increasing 
it the Northampton distribution centre trailer load are increasing from 160 to 225 per day. The increment is affecting the gate house, trailer parking and loading bays.

By solving the problem, they have used witness simulation and the witness simulation modelled shows that a second gatehouse lane is needed. Then they built it and implement it on May 2010 [9]. Figure below shows the witness simulation model by Coca Cola.

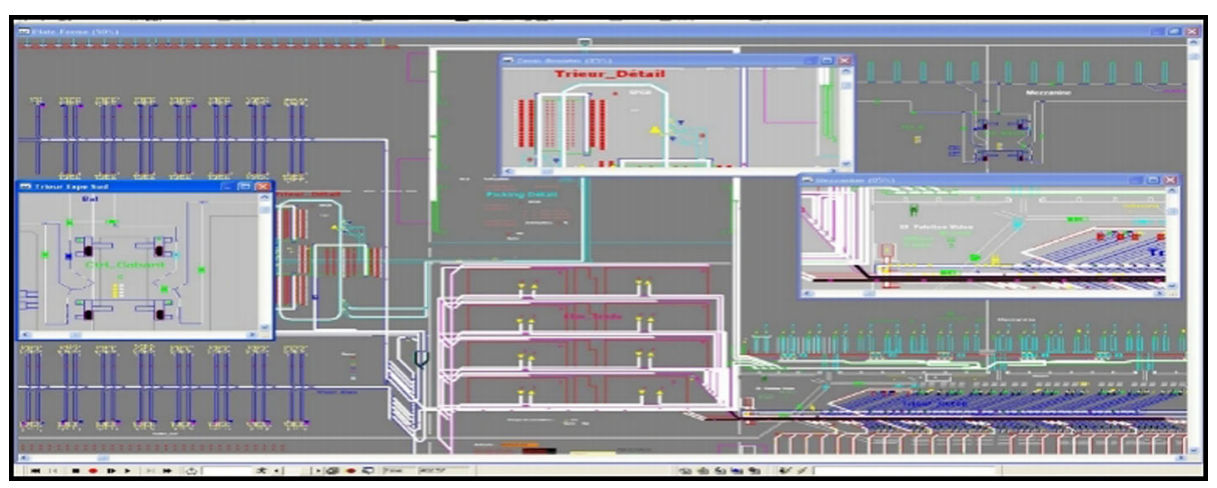

Fig. 2. Supply chain Coca Cola model

\section{Methodology/materials}

\subsection{Introduction}

Methodology is a research method that will be used to acquire data or information through the research process. This research is planned carefully as to ensure the research that carried succeed to achieve the research objective or aim. Research design provides an overall for the collection and analysis of the data.

\subsection{Source of information}

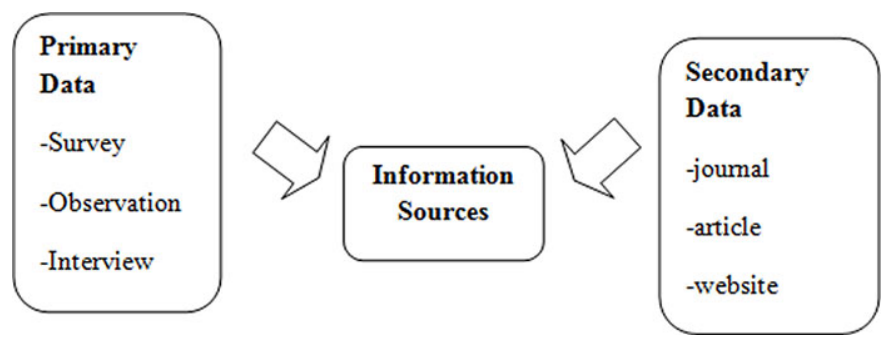

Fig. 3. Source of information 
Primary data. Primary data collection technique is consisting of two types of data which are qualitative and quantitative data. For this research, the researcher uses the qualitative data because it is suitable to know if the problem of effectiveness in their operation line is really happened.

Secondary data. Secondary data is used to support the research and to make the research stronger and more exciting while read it. The secondary data information can be found from various types of information such as books, journals, websites and articles that are related to the research regarding to the effectiveness problem, and the witness simulation model is to solve the effectiveness problem.

Observation for data collection. The data collection of this study is taken by having an observation at LGL technology at their operation line to see the current situation of operation. By having an observation, the researcher identified the problem of this study is due to lack of machinery that would affect the operation time effectiveness.

The data that have been collected will be used as an output in the witness simulation to get the input. From the result, we can see which is more effective, automated machine witness simulation or manual machine.

Interview for data collection. This step describes the process that involved in interview and for the data collection. The researcher must follow the step-in order to avoid difficulties as to meet the objective.

Interview is the two way of communication which permits an exchange of idea and information. The interview session will be a conversation that focus on the title of the research to find the objectives of the research. In interview session, interviewer can explain more about the research to the interviewee and gain the specific answer or information that required for the research.

For this research, the researcher used two types of interviews such as structured interview which means the structured interviews are rigidly standardized and follow a list of previously prepare questions. Second types of interviews used by the researcher are semi-structured interviews. From these interviews, the interviewers ask some previously prepared questions as well as unprepared questions based on the answers of the interviewees.

\section{$4 \quad$ Finding $\&$ analysis}

The method uses to collect the data that are needed to be used in the modelling comes from the interview sessions with the manager of LGL Technology Sdn Bhd as he is the Head of the Operation itself, so he has the knowledge to answer the interview questions.

\subsection{Research objective 1}

The first research objective for this research is to study the existing effectiveness of manual machine in LGL Technology Sdn Bhd. In order to meet the research objective there is a need to identify a suitable model. The research question below was created: 
Research question 1. What is the suitable model to identify the current effectiveness of operational line in LGL technology?

1. Method. In order to answer research question one, the researcher conducted a simulation for the existing effectiveness of manual machine in LGL Technology Sdn Bhd by using Witness Simulation Software that has been explained previously in Chapter 2 and Chapter 3.

2. Witness Simulation Model. Witness Simulation Model is used to imitate the realworld situation and it has most of the design element that can be used to imitate the real situation of production line. The problem regarding the effectiveness can be solved or reduced based on the system statistic. By getting the statistic after implementing the data found from the interview sessions it can either solve the problem or reduce the problem of effectiveness at LGL Technology operation line.

3. Design element used in witness simulation. The simulation model of improvement of operation at LGL industries was designed by using design element of witness simulation software. Every element has their own function to show the process of operation in LGL industries by using milling machine. There are two designs that is current design and the proposed design to increase the effectiveness of LGL Industries operation. All the design process from the beginning to end was transformed into the simulation model as to display the process that is similar to real life process.

$i$. Part. Part that will be used in the modeling will act as the raw material. The example of material uses by LGL companies such as steel and aluminum. The part will be located at the shelf that is separated from the operation site. The part will be moved by the worker from the shelf to the machine to process the material to be a finished product. Although there will be two different designs, the location of part and the movement of part by worker are the same.

ii. Buffer. Raw material shelf is the buffer used in the design. Buffer counts are selected because it has prepared with numbering that will be easier to determine the number of materials on the shelf. The shelf is used to hold the part before the worker moving it to the machine. The shelf location is separate from the operation line.

There is also a buffer at the end of the process that act as carton box. There is a need for the carton box to easier the process to taken out the statistic of the operation. There are 4 numbers of carton boxes besides milling machine. The number and the location are the same between current and proposed design.

iii. Machine. There are 9 machines used in the design, but there are only 4 machines that will be used compared to their effectiveness in the design.

The first design is the current design, the current design will be having same amount of machine that is 9 and the important 4 machine that will be a manual milling machine. The designer element use for the 4 machine is an ordinary machine in blue colour that acts as the milling machine. 
Second design is the proposed design, the proposed design will be having same amount of machine that is 9 and the important 4 machine will be an automatic CNC milling machine, the designer element use for the 4 machine is a $\mathrm{CNC}$ machine that can be found in the update graphic.

$i v$. Labor. The current design and proposed design will have same amount of labor use. The labor use in the design act as technician. The use of the labor is to move the raw material from the shelf to the machine.

In the current design the labor will manually operate the raw material until it become a finish product and the proposed design labor will only place the material on the CNC machine and waiting as the machine itself is automatic. The location of labor will be beside the shelf before the movement and beside machine to operate the machine.

v. Layout. The use of layout is to ensure the design of the model is important as to imitate the real-life situation at the LGL industries. The layout design will be the same in the current and also proposed design.

vi. Path. The use of path is to link the labor from shelf to the machine by taking the raw material on the shelf and sent to machine to proceed with the operation. Current and proposed design will be using the same type of layout. There are 4 paths used to link the labor from the shelf to machine to set them to follow the movement using the designated path.

\subsection{Research objective 2}

The second objective for this research is to develop a simulation on the effectiveness of manual machine and effectiveness of using automated machine in LGL Technology Sdn Bhd operation line. The research question below was created:

Research question 2. How to develop a simulation to identify the effectiveness of automated and manual machine in operational line?

$i$. Development. The complete simulation model of the current design and proposed design of operational line at LGL industries. The design will be shown in $2 \mathrm{D}$ and also 3D model. 


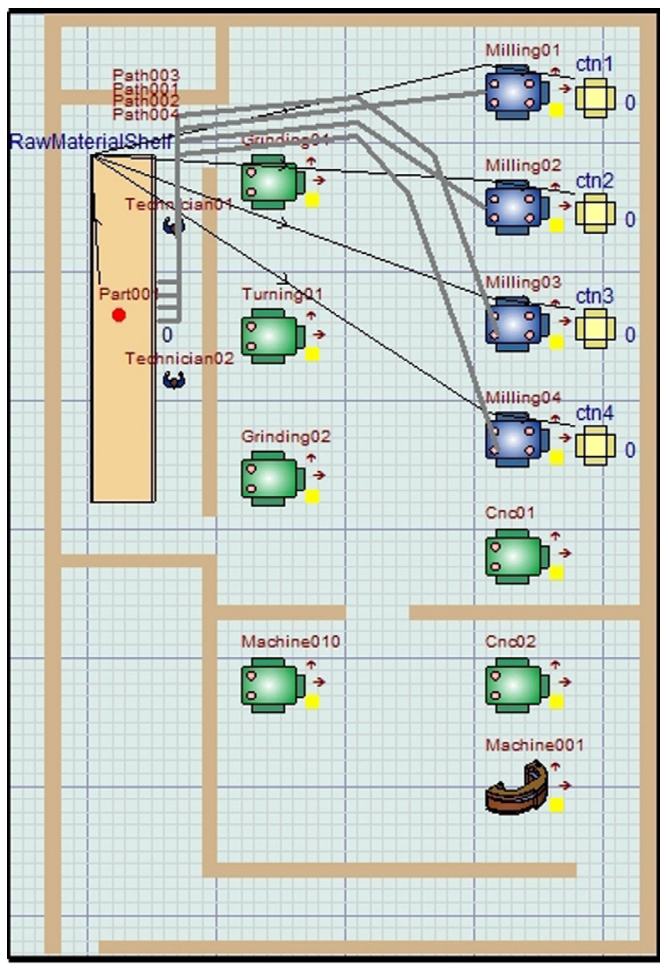

Fig. 4. The final development of simulation model for current design in 2D model

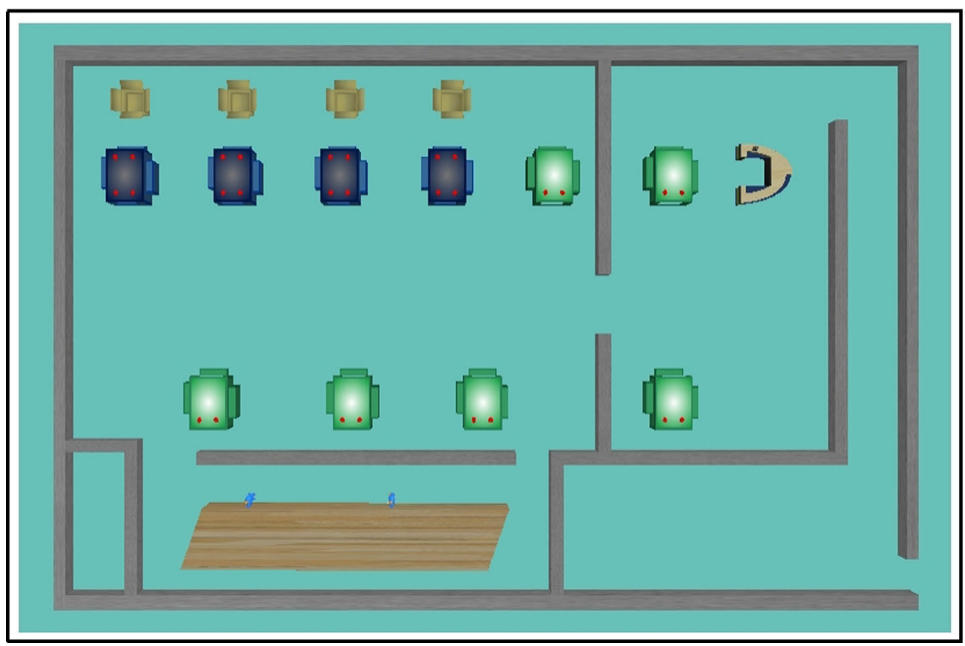

Fig. 5. 3D model development for current design from above 


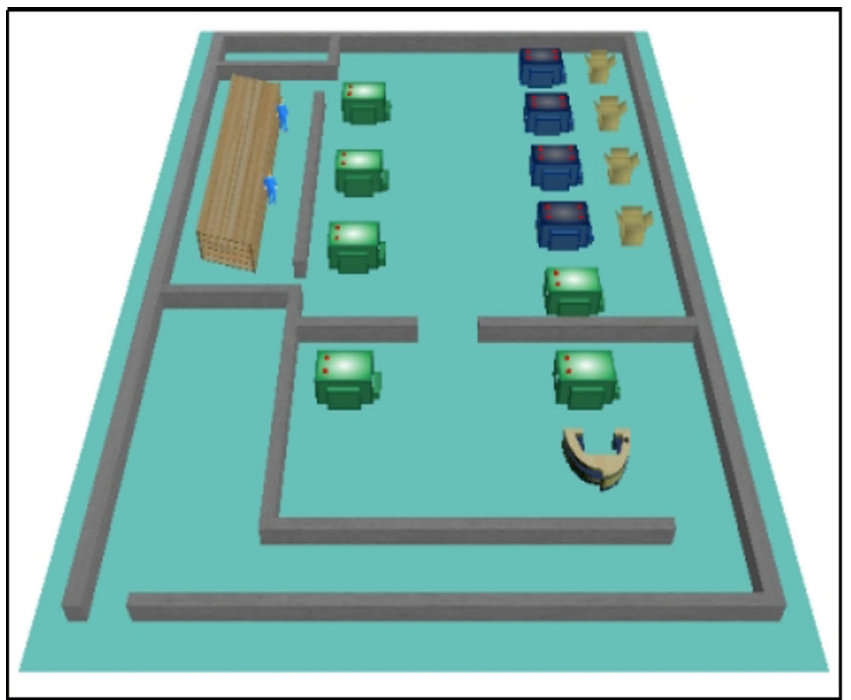

Fig. 6. 3D model development for current design from front

\section{b. Proposed design}

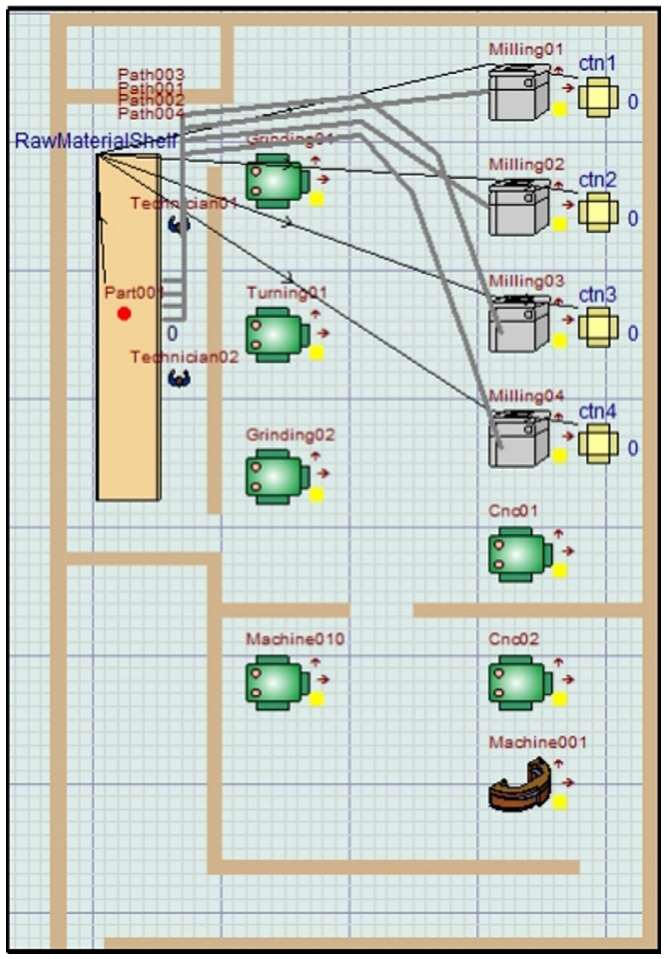

Fig. 7. The final development of simulation model for proposed design in 2D mode 


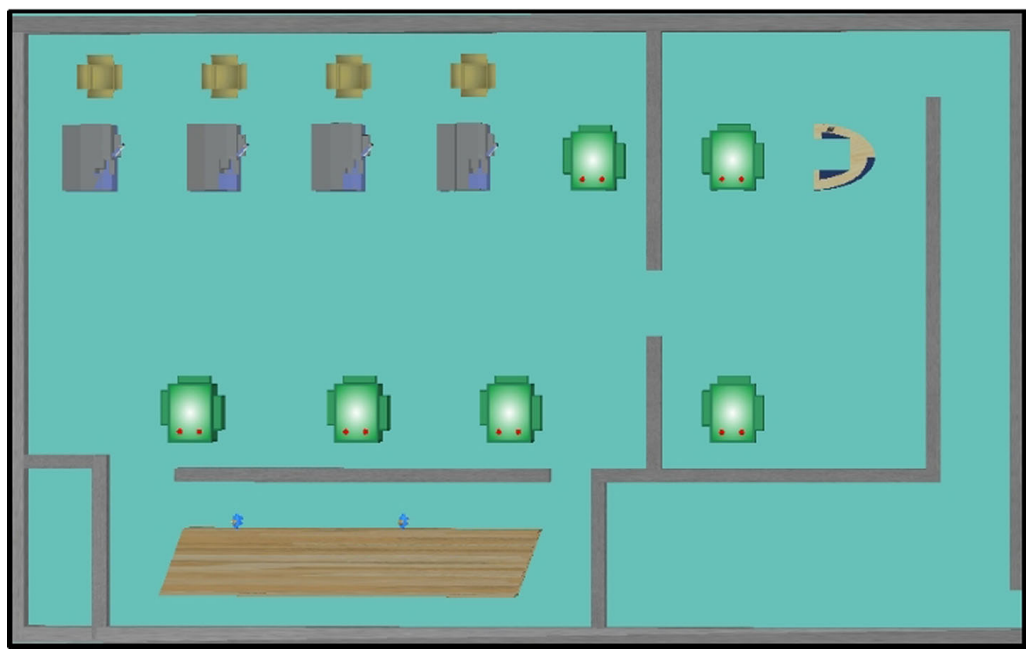

Fig. 8. 3D model development for proposed design from above

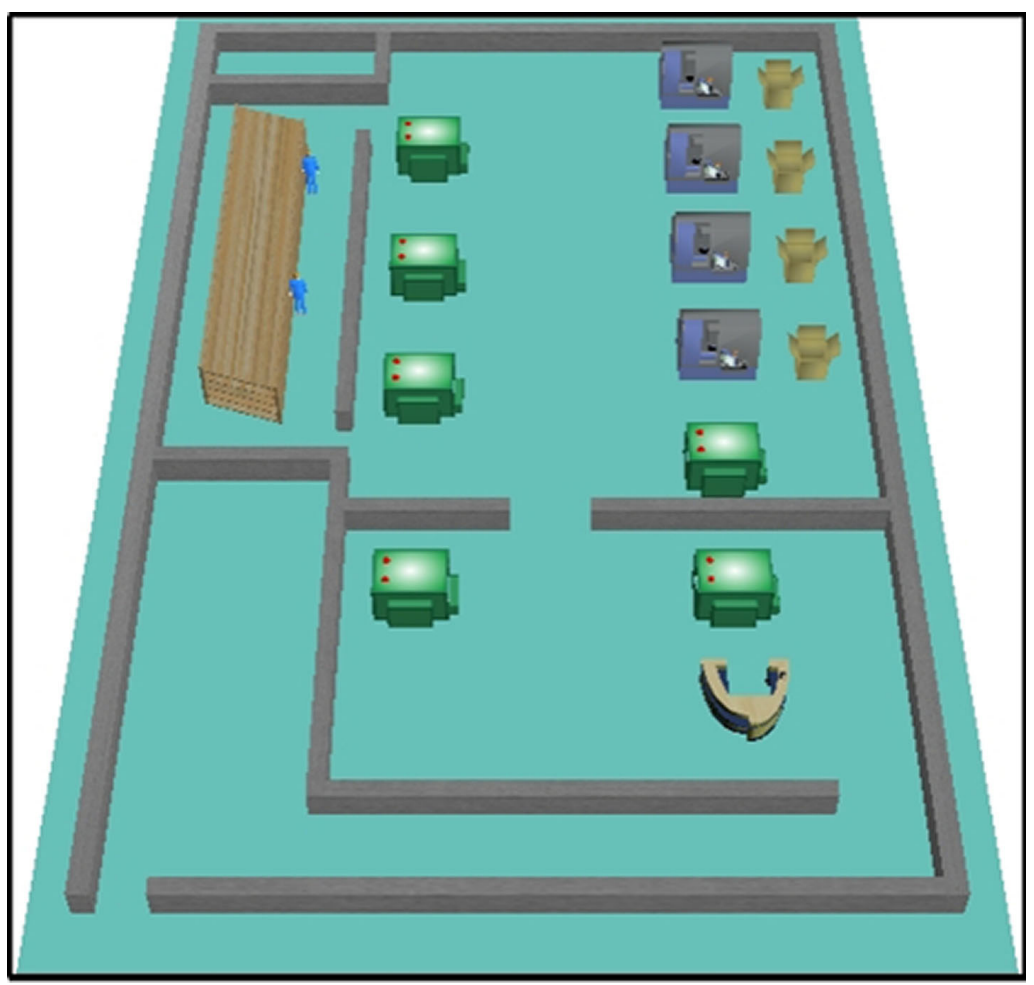

Fig. 9. 3D model development for proposed design from front 


\subsection{Research objective 3}

The third objective for this research is to evaluate the difference about the effectiveness of automated and manual machine in terms of time and output at LGL Technology Sdn Bhd operation line.

Research question 3. What is the effectiveness of automated and manual machine?

Table 1. Coding interview

\begin{tabular}{|c|c|c|}
\hline No & Question & Answer \\
\hline 1 & Sir, what is the size of this company? & This company size is $24 \times 85$ feet only. \\
\hline 2 & $\begin{array}{l}\text { How many numbers of machine did the } \\
\text { company have? }\end{array}$ & We have total of 9 machines here. \\
\hline 3 & $\begin{array}{l}\text { What is the type of machine did you have } \\
\text { here? }\end{array}$ & $\begin{array}{l}\text { We have } 5 \text { types of machines like grinding, } \\
\text { mining, turning, milling and turning machine }\end{array}$ \\
\hline 4 & How many workers did you have here? & $\begin{array}{l}\text { We have } 8 \text { workers that working in this } \\
\text { company, and they are working by shift. } \\
\text { One worker for } 2 \text { machines. }\end{array}$ \\
\hline 5 & $\begin{array}{l}\text { What are the common problems you facing } \\
\text { that are related to the operation? }\end{array}$ & $\begin{array}{l}\text { Most of the problem comes from the } \\
\text { operation itself such as quality problem due } \\
\text { to the number of order and shorter time to } \\
\text { produce it and as you know our company } \\
\text { focuses on produce fabrication item that } \\
\text { are needed to be precise. }\end{array}$ \\
\hline 6 & $\begin{array}{l}\text { What is the daily output that your company } \\
\text { produces per day? }\end{array}$ & $\begin{array}{l}\text { The numbers of output are that we can } \\
\text { produce per day is } 400 \text {. }\end{array}$ \\
\hline 7 & $\begin{array}{l}\text { May I get your company layout blueprint for } \\
\text { my research? }\end{array}$ & $\begin{array}{l}\text { I can give our original old blueprint by the } \\
\text { name of Southtec precision engineering. }\end{array}$ \\
\hline 8 & $\begin{array}{l}\text { As per my observation here, there is several } \\
\text { manual machine and automated machine how } \\
\text { long the worker spent on finishing } 1 \text { item? }\end{array}$ & $\begin{array}{l}\text { Ok, usually for the manual machine they } \\
\text { need until } 120 \text { minutes as to finish the item } \\
\text { this is because they need to do it carefully } \\
\text { as to ensure their quality. }\end{array}$ \\
\hline
\end{tabular}

\subsection{Statistic results}

The design would not be complete without any data receives from observation and also interview session. The changes are made on the cycle time machine as per manual machine is 120 minutes and automated machine is 30 minutes as per detail received from the interview (Table 1 Coding of the interview).

The way on getting the result is divided by two elements that is by time setting and also fixes number of raw materials. 


\section{Result I: Time setting}

i. Current design (Manual Machine)

\begin{tabular}{|c|c|c|c|c|}
\hline \multicolumn{5}{|l|}{$\Phi$ WITNESS } \\
\hline \multicolumn{5}{|c|}{ Buffer Statistics Report by Total Simulation Time } \\
\hline Name & $\operatorname{ctn} 1$ & $\operatorname{ctn} 2$ & $\operatorname{ctn} 3$ & $\operatorname{ctn} 4$ \\
\hline Total In & 2 & 1 & 2 & 1 \\
\hline Total Out & 0 & 0 & 0 & 0 \\
\hline Now in & 2 & 1 & 2 & 1 \\
\hline $\operatorname{Max}$ & 2 & 1 & 2 & 1 \\
\hline Min & 0 & 0 & 0 & 0 \\
\hline Avg Size & 0.81 & 0.43 & 0.67 & 0.36 \\
\hline Avg Time & 195.25 & 204.02 & 161.46 & 173.68 \\
\hline \multicolumn{5}{|l|}{ Avg Delay C } \\
\hline \multicolumn{5}{|l|}{ Avg Delay Ti } \\
\hline Min Time & 0.00 & 0.00 & 0.00 & 0.00 \\
\hline Max Time & 326.27 & 204.02 & 295.93 & 173.68 \\
\hline$\%$ Off-Shift & & & & \\
\hline
\end{tabular}

Fig. 10. Statistic for current design based on time setting

Figure 12 above shows the model is running with a fix time of 480 that is consider as 8 hours working. By setting at 480, the researcher can know the number of output that can be produced at that time. Based on Figure 12, the number of output after 8 hours is 6 . This is due to the cycle time of machine is at 120 minutes as per detail received from the interview (Table 1).

ii. Current design (Manual Machine)

\begin{tabular}{|c|c|c|c|c|}
\hline \multicolumn{5}{|l|}{ WITNESS } \\
\hline \multicolumn{5}{|c|}{ Buffer Statistics Report by Total Simulation Time } \\
\hline Name & ctn1 & $\operatorname{ctn} 2$ & ctn3 & $\operatorname{ctn} 4$ \\
\hline Total In & 5 & 4 & 4 & 4 \\
\hline Total Out & 0 & 0 & 0 & 0 \\
\hline Now in & 5 & 4 & 4 & 4 \\
\hline $\operatorname{Max}$ & 5 & 4 & 4 & 4 \\
\hline Min & 0 & 0 & 0 & 0 \\
\hline Avg Size & 2.44 & 1.90 & 1.92 & 1.38 \\
\hline Avg Time & 234.70 & 228.35 & 230.79 & 165.73 \\
\hline \multicolumn{5}{|l|}{ Avg Delay C } \\
\hline \multicolumn{5}{|l|}{ Avg Delay Ti } \\
\hline Min Time & 0.00 & 0.00 & 0.00 & 0.00 \\
\hline Max Time & 416.27 & 384.02 & 385.93 & 353.68 \\
\hline$\%$ Off-Shift & & & & \\
\hline
\end{tabular}

Fig. 11. Statistic for proposed design based on time setting 
As per Figure 13 the model is running with a fix time of 480 that is consider as 8 hours working. By setting at 480 , the researcher can know the number of outputs that can be produced at that time. Based on Figure 13, the number of outputs after 8 hours is 17. This is due to the cycle time of machine is at 30 minutes as per detail received from the interview (Table 1).

Table 2. Summary for result 1 : Time setting

\begin{tabular}{|l|c|c|}
\hline & Output/Unit & Effectiveness/Output \\
\hline Current Design & 6 unit & \\
\hline Proposed Design & 17 unit & $/$ \\
\hline
\end{tabular}

Based on Table 2 summary for result 1 time setting, it shows that the current design with manual machine can produce output of 6 units and proposed design with automated machine can produce 17 units. It shows that the proposed design with automated machine is more effective compared to the current design with manual machine.

\section{Result II: Fixed number of material}

\section{i. Current design (Manual Machine)}

\begin{tabular}{|c|c|c|c|c|}
\hline \multicolumn{5}{|l|}{ WITNESS } \\
\hline \multicolumn{5}{|c|}{ Buffer Statistics Report by Total Simulation Time } \\
\hline Name & ctn1 & $\operatorname{ctn} 2$ & $\operatorname{ctn} 3$ & $\operatorname{ctn} 4$ \\
\hline Total In & 1 & 1 & 1 & 1 \\
\hline Total Out & 0 & 0 & 0 & 0 \\
\hline Now in & 1 & 1 & 1 & 1 \\
\hline $\operatorname{Max}$ & 1 & 1 & 1 & 1 \\
\hline Min & 0 & 0 & 0 & 0 \\
\hline Avg Size & 0.50 & 0.10 & 0.40 & 0.00 \\
\hline Avg Time & 152.59 & 30.34 & 122.25 & 0.00 \\
\hline \multicolumn{5}{|l|}{ Avg Delay C } \\
\hline \multicolumn{5}{|l|}{ Avg Delay Ti } \\
\hline Min Time & 0.00 & 0.00 & 0.00 & 0.00 \\
\hline Max Time & 152.59 & 30.34 & 122.25 & 0.00 \\
\hline$\%$ Off-Shift & & & & \\
\hline
\end{tabular}

Fig. 12. Statistic for current design based on fix number of materials

Figure 14 shows the model is running with a fix number of raw materials that is 4 raw materials. This test is to know the time needed for a transforming of 4 raw materials into finished goods. Based on Figure 14, the average time needed to produce 4 finished products is $\mathbf{1 5 2 . 5 9}+\mathbf{3 0 . 3 4}+\mathbf{1 2 2 . 2 5}=\mathbf{3 0 5 . 1 8}$ minutes. 
ii. Proposed design (Automated machine)

\begin{tabular}{|c|c|c|c|c|}
\hline \multicolumn{5}{|l|}{$\Psi$ WITNESS } \\
\hline \multicolumn{5}{|c|}{ Buffer Statistics Report by Total Simulation Time } \\
\hline Name & $\operatorname{ctn} 1$ & $\operatorname{ctn} 2$ & $\operatorname{ctn} 3$ & $\operatorname{ctn} 4$ \\
\hline Total in & 1 & 1 & 1 & 1 \\
\hline Total Out & 0 & 0 & 0 & 0 \\
\hline Now in & 1 & 1 & 1 & 1 \\
\hline $\operatorname{Max}$ & 1 & 1 & 1 & 1 \\
\hline $\operatorname{Min}$ & 0 & 0 & 0 & 0 \\
\hline Avg Size & 0.50 & 0.24 & 0.26 & 0.00 \\
\hline Avg Time & 62.59 & 30.34 & 32.25 & 0.00 \\
\hline \multicolumn{5}{|c|}{ Avg Delay Count } \\
\hline \multicolumn{5}{|c|}{ Avg Delay Time } \\
\hline Min Time & 0.00 & 0.00 & 0.00 & 0.00 \\
\hline Max Time & 62.59 & 30.34 & 32.25 & 0.00 \\
\hline$\%$ Off-Shift & & & & \\
\hline
\end{tabular}

Fig. 13. Statistic for proposed design based on fix number of materials

Figure 15 shows the model is running with a fix number of raw materials that is 4 raw materials. This test is to know the time needed for a transforming of 4 raw materials into finished goods. Based on Figure 15, the average time needed to produce 4 finished products is $62.59+30.34+32.25+0=125.18$ minutes.

Table 3. Summary for result 2: Fixed number of material

\begin{tabular}{|l|c|c|}
\hline & Time/Minutes & Effectiveness/Output \\
\hline Current Design & 305.18 minutes. & \\
\hline Proposed Design & 125.18 minutes. & $/$ \\
\hline
\end{tabular}

Based on Table 3 summary for result 2 fixed numbers of materials, it shows that the current design with manual machine can produce output of 4 units in 305.18 minutes and proposed design with automated machine can produce 4 units in 125.18 minutes. It shows that the proposed design with automated machine is more effective compared to the current design with manual machine.

\subsection{Conclusion}

As conclusion, the researcher used an interview to get the data and to ensure all the data is valid to be used in the simulation for the operation of LGL Technology Sdn Bhd. This chapter also proves that using simulation to the current design of manual machine is less effective compared to the proposed design with the automated machine. Using the simulation can helps to solve the problem of effectiveness in LGL Technology Sdn Bhd operation. It also helps the researcher to know the right design to solve the problem based on the title of the research. 


\section{Conclusion}

\section{$5.1 \quad$ Introduction}

This chapter consists of the brief explanation and summarizing of result and finding that was gained from the previous chapter based on the data collected that had been analyzed. It is important so that the reader can easily capture and conclude what are the findings in this research. This chapter also shows whether the finding is related to the objective of the study.

\subsection{Recommendation}

Using the new technology. Based on the research, the researcher finds that LGL Technology Sdn Bhd had a problem in terms of delay and quality. To improve the company effectiveness, there is a need to consider using a new technology because new technology will offer better performance compared to old type of machine. Machines that require manual operation to operate were insufficient to achieve an optimum level of performance for their company due to the company are producing item based on precision or fabrication item which are required to be precise and pristine condition without any error.

When changing to automatic machine, the manpower is only needed to set up the machine and no manpower is needed to handle the machine to process the raw material to finish product.

Blanket order. There is a need for LGL Technology Sdn Bhd to consider the importance of using blanket order. The company needs to suggest to the customer ordering through blanket order. LGL Technology supply item that needs a precision and needs to take time to ensure the quality. But LGL Technology has a problem due to delay.

This is because the customer order in a short time of ETA (estimated time arrival). Blanket order is a purchase order which the customer can place an order by a multiple of delivery date over a period of time. This will benefit two parties as for LGL itself it can prepare the order earlier to fulfil the order on time. Then, the customer can get their item on time compared to sudden or urgent order.

Training. Based on the observation, most of LGL workers did not have knowledge or experience on using automatic machine. There is a need to consider training to enhance their skill in terms of machine and also the soft skill. Training is important to ensure they know on how to use the machine.

Increasing the number of workers. Based on the research, the researcher suggests that there is a need for increasing of work force due to now they only have 8 workers that is 4 in the mid-day and others on the night shift. Based on the interview, their daily output can exceed up to 400 unit. By increasing the number of workforces, it can reduce the time on producing the item per day.

\subsection{Contribution}

Based on the objective, this research is to identify the effectiveness of automated machine over manual machine in operation line. The results from interview, observation 
and also statistic from the modeling that has been done bring useful information to make an analysis and further idea to be implemented by the manufacturer. It also gives benefit to the customer.

Contribution to the manufacturer. By conducting this research, the manufacturer or the company itself can use it to make improvement in their operational line to gain more customer and also profit. Based on the interview that had been conducted, they had a problem in terms of delay due to the number of orders that are excessive, and they are rushing on producing the item. So, when the operational are rushing on making the item, it will affect the level of quality. Hence, by changing the manual to the automatic machine it will reduce time needed to produce it and by a short time it can produce more than a manual machine.

Contribution to the customer. This research shows how the automatic machine can be effective in terms of time to reduce the delay problem. When the company can produce the goods in a shorter time it will benefit the customer. When there is no interference of manpower and by using $100 \%$ of machine the quality level of the goods is better compared by using a manual machine. So, when the customers are satisfied, they will be happy to reorder from the manufacturer.

\subsection{Conclusion}

As for conclusion, the improvement of the operational line at LGL Technology to ensure that they can fulfill their customer order by an estimated time needed and also with a good quality. By changing to the automated machine, it will provide varieties of benefits either to the manufacturer itself or also will be beneficial to the customer. From the observation, there are several things that need to be improved to increase their operational line effectiveness especially in terms number of machines.

\section{References}

[1] Cummings, M. (2017). Man versus Machine or Man + Machine? (pp. 3-4). Arizona: Expert Opinion. Retrieved from https://hal.pratt.duke.edu/sites/hal.pratt.duke.edu/files/u10/IS-2905-Expert $\% 200$ pinion $\% 5 \mathrm{~B} 1 \% 5 \mathrm{D} \quad 0 . \mathrm{pdf}$

[2] Ford, S., \& Despeisse, M. (2016). Additive manufacturing and sustainability: an exploratory study of the advantages and challenges. Journal of Cleaner Production, 137, 1573-1587. https://doi.org/10.1016/j.jclepro.2016.04.150

[3] Gorbis, M. (2011). Human plus Machine (pp. 1-6). 2011: Institute for the future. Retrieved from http://www.iftf.org/uploads/media/Human_Plus_Machine_MG_sm.pdf

[4] Gummesson, E. (2014). Productivity, quality and relationship marketing in service operations: A revisit in a new service paradigm. International Journal of Contemporary Hospitality Management, 26(5), 656-662. https://doi.org/10.1108/IJCHM-01-2014-0017

[5] Harris, J. (2017). Man, vs machine: 9 human jobs taken over by robots. BT.com. Retrieved 1 July 2017, from http://home.bt.com/tech-gadgets/future-tech/man-vs-machine-9-jobsovertaken-by-robots-11364003046052

[6] Lateef, F. (2010). Simulation-based learning: Just like the real thing. Journal of Emergencies, Trauma and Shock, 3(4), 348. https://doi.org/10.4103/0974-2700.70743 
[7] Mohd Noor, H. A., Ab Manaff, J. A., Kassim, R., Abdul Rahman, F., \& Baharum, Z. (2020). Assessing The Performance of Direct Activities In Palm Oil Mill, Kelantan. Journal of Critical Reviews, 7(8). https://doi.org/10.31838/jcr.07.07.01

[8] Montazer, M. Ali, KursadEce, and Hakan Alp. "Simulation Modeling In Operations Management”.N. p., 2003. Web. 13 Oct. 2016.

[9] Pholsuwanachai, K. (2011). A Courier Company's Service Performance \& Customer Satisfaction. Journal of Supply Chain Management, 5(1).

[10] Waller, Tonny. "Witness Simulation and Its Role in Decision Support". ewgdssliverpool2012. N.p., 2012. Web. 13 Oct. 2016.

[11] Khan, N., \& Qureshi, M. A systematic literature review on online medical services in Malaysia.

[12] Mustapha, I., Van, N. T., Shahverdi, M., Qureshi, M. I., \& Khan N. (2021) Effectiveness of Digital Technology in Education During COVID-19 Pandemic. A Bibliometric Analysis. International Journal of Interactive Mobile Technologies. 15(8). https://doi.org/10.3991/ ijim.v15i08.20415

[13] Qureshi, M. I., Khan, N., Raza, H., Imran, A., \& Ismail, F. (2021) Digital Technologies in Education 4.0. Does it Enhance the Effectiveness of Learning? A Systematic Literature Review. International Journal of Interactive Mobile Technologies. 15(4). https://doi. org/10.3991/ijim.v15i04.20291

[14] Fuada, S., Adiono, T., \& Siregar, L. (2021). Internet-of-Things for Smart street lighting system using ESP8266 on mesh network. International Journal of Recent Contributions from Engineering, Science \& IT (IJES), 9(2), 73. https://doi.org/10.3991/ijes.v9i2.22877

[15] Boettcher, K., \& Behr, A. (2021). Using virtual reality for teaching the derivation of conservation laws in fluid mechanics. International Journal of Engineering Pedagogy (IJEP), 11(4), 42. https://doi.org/10.3991/ijep.v11i4.20155

[16] Kapucu, H. (2021). Business leaders' perception of digital transformation in Emerging Economies: On leader and Technology Interplay. International Journal of Advanced Corporate Learning (IJAC), 14(1), 43. https://doi.org/10.3991/ijac.v14i1.21959

\section{Authors}

Helmi Adly bin Mohd Noor, Doctor of Philosophy, Department of Technical Foundation, Universiti Kuala Lumpur-Malaysian Institute of Industrial Technology, Persiaran Sinaran Ilmu, Bandar Seri Alam, 81750 Johor Bahru, Johor, Malaysia. Email: helmiadly@gmail.com/helmiadly@unikl.edu.my

Muhamad Nor Sadiqin Bin Ramli, Bachelor of Industrial Logistics, Universiti Kuala Lumpur, Malaysia Institute of Industrial Technology.

Rahimah Kassim, Department of Technical Foundation, Universiti Kuala Lumpur-Malaysian Institute of Industrial Technology, Persiaran Sinaran Ilmu, Bandar Seri Alam, 81750 Johor Bahru, Johor, Malaysia. Email: rahimahk@unikl.edu.my

Fauziah Abdul Rahman, Department of Technical Foundation, Universiti Kuala Lumpur-Malaysian Institute of Industrial Technology, Persiaran Sinaran Ilmu, Bandar Seri Alam, 81750 Johor Bahru, Johor, Malaysia. Email: fauziahar@unikl.edu.my

Zirawani Baharum, Doctor of Philosophy in Computer Science, Department of Technical Foundation, Universiti Kuala Lumpur-Malaysian Institute of Industrial Technology, Persiaran Sinaran Ilmu, Bandar Seri Alam, 81750 Johor Bahru, Johor, Malaysia. Email: zirawani@unikl.edu.my 
Farah Idayu Mohd Salleh, Department of Student Development, Universiti Kuala Lumpur-Malaysian Institute of Industrial Technology, Persiaran Sinaran Ilmu, Bandar Seri Alam, 81750 Johor Bahru, Johor, Malaysia. Email: farahidayu@unikl.edu.my

Article submitted 2021-06-11. Resubmitted 2021-08-26. Final acceptance 2021-08-28. Final version published as submitted by the authors. 